Кліндухова В.М., Гейлик А.В., Ляшко О.В.

\title{
МОДЕЛЮВАННЯ ДЕЯКИХ ОБ'СКТІВ ЗАСОБАМИ ІНТЕГРАЛЬНОГО ЧИСЛЕННЯ СТУДЕНТАМИ МОЛОДШИХ КУРСІВ МОРСЬКИХ СПЕЦІАЛЬНОСТЕЙ
}

Стаття присвячена актуальному питанню прикладної спрямованості дисичилін математичного ичиклу, моделювання інженерних процесів засобами традиційного курсу вищої математики та використання теорї центру мас.

Питання інтегрованості компетентностей професійної підготовки фахівців річкового та морського транспорту в систему математичних дисииплін завжди викликало зацікавленість. Враховуючи, щзо дана спеціальність є регульованою та імплементованою у світове товариство, до математичних знань студентів молодших курсів морських спеціальностей висувається низка вимог. Зауважено, щзо деякі питання інженерної математики відображенні в міжнародних вимогах Модальних курсів IMO та, в той самий час, не зовсім повністю відображені в курсі математичних дисциплін морських $3 В О$.

Запропоновані задачі повною мірою відображають зв'язок математичної підготовки з освітньо-професійними програмами підготовки фахівців річкового і морського транспорту, Стандартними вищої освіти України та міжнародними вимогами ІМО. Кожна задача включає коментар до розв'язання, а також розглядається з позицій як традиційності викладання вищої математики, так $i$ за допомогою теорії про центр мас.

В свою чергу, інтегральний метод розв'язання задач на знаходження центроїду, дозволяє не лише вдосконалити базові знання з вищої математики, а й зацікавити та вмотивувати студента до підвищення рівня математично-професійних навичок, формування професійних задач на основі фундаментальних математичних тверджень, методів, засобів.

Подальшого дослідження потребують питання розробки та вдосконалення методичної системи завдань дисциплін математичного циклу у відповідності до вимог освітньопрофесійних програм підготовки фахівиів річкового та морського транспорту, Стандартів вищої освіти та Модальних курсів IМО. В аспекті ияього напряму розвитку досліджень особливої уваги потребують конщептуальні питання Higher Engineering Mathematics, інтегровність математичних та професійних компетентностей.

Ключові слова: моделювання об'єктів, підготовка фахівиів річкового $i$ морського транспорту, професійно-математична підготовка, центроїд, барицентр, центр мас

Постановка проблеми Зв'язок професійно - математичної підготовки 3 освітньо професійними програмами підготовки фахівців річкового і морського транспорту забезпечує якість математичної освіти у відповідності до сформованих результатів навчання, як в Стандарті вищої освіти України [10], так і в Модельних курсах IMO [6,7,8]. Уміння студентів молодших курсів морських спеціальностей визначаються за видами навчальної діяльності. Конкретизація загальних і професійних компетентностей здійснюється, зокрема, в: програмі навчальної дисципліни «Вища математика», практичних заняттях, індивідуальних завданнях, і застосовується як критерії відбору необхідних знань, які можна ідентифікувати, кількісно оцінити та виміряти.

Наразі фахівець повинен мати високий рівень професійно-математичної підготовки, яка передбачає освіту, що включає оволодіння необхідними знаннями у галузі математика для забезпечення необхідних для фахівця достатнього рівня інтегральних, загальних та фахових 
компетентностей, комунікації у сферах професійного та ситуативного спілкування. Успішне оволодіння базовою математичною підготовкою передбачає здобуття особою, якій присвоюється кваліфікація, знань, умінь та навичок, необхідних для розв'язування спеціалізованих професійних задач з елементами математичного моделювання.

Аналіз останніх досліджень і публікацій. Спираючись на Стандарт вищої освіти України спеціальності 271 - Річковий та морський транспорт [10], Model Course by IMO [6,7,8] та Higher Engineering Mathematics [2,3], можемо стверджувати, що інтегральна компетентність [11] професійно-математичної підготовки, що виражає основні компетентносні характеристики рівня вищої освіти бакалавр щодо навчання дисциплін математичного циклу, забезпечує розв'язання спеціалізованих задач та практичних проблем у професійній діяльності та передбачає застосування математичних теорій та методів.

На основі проведеного аналізу досліджень і публікацій, можемо стверджувати, що структурно-логічна схема побудови інтегральної компетентності професійно-математичної підготовки забезпечується такими загальними компетенностями, як:

- здатність застосовувати знання у практичних ситуаціях;

- знання та розуміння предметної області та розуміння професійної діяльності,

А також діяльністю із застосуванням математичних методів, зокрема:

- здатність використовувати математичні теорії, методи та прийоми;

- здатність обирати та застосовувати математичні методи для розв'язання прикладних задач, в тому числі моделювання, аналізу, проектування, керування, прогнозування, прийняття рішень;

- здатність до проведення математичного обчислювального експерименту, розв'язання формалізованих задач;

здатність зрозуміти та сформулювати математичну постановку задачі, спираючись на постановку мовою предметної галузі, та обирати метод іiї розв'язання, що забезпечує потрібні точність і надійність результату.

В свою чергу, професійно-математична підготовка фахівця морської галузі забезпечую такі програмні результати навчання:

формалізувати задачі, сформульовані мовою певної предметної галузі; формулювати їх математичну постановку та обирати раціональний метод вирішення; розв'язувати отримані задачі аналітичними та чисельними методами, оцінювати точність та достовірність отриманих результатів;

будувати ефективні щодо точності обчислень, стійкості, швидкодії та витрат системних ресурсів алгоритми для чисельного дослідження математичних моделей та розв'язання практичних задач;

володіти методиками вибору раціональних методів та алгоритмів розв'язання математичних задач оптимізації, дослідження операцій, оптимального керування і прийняття рішень, аналізу даних;

розв'язувати окремі інженерні задачі та/або задачі, що виникають принаймні в одній предметній галузі професійної діяльності;

- збирати та інтерпретувати відповідні дані й аналізувати складності в межах своєї спеціалізації для донесення суджень, які відбивають відповідні соціальні та етичні проблеми.

Виділення невирімених раніме частин загальної проблеми. В основу планування освітньо -математичної траєкторії формування майбутнього фахівця спеціальності 271 Річковий та морський транспорт у Модельних курсах IMO та Стандартах вищої освіти України покладено прагматичний, компетентнісно орієнтований підхід. До програм дисциплін включається не лише матеріал для формування у студентів єдиної цілісної інженерної математичної освіти, а й матеріал, який у подальшому буде необхідний для оволодіння певними професійними компетенціями. При цьому зустрічаються певні змістові елементи дисципліни, що $є$ непритаманними традиційному курсу вищої математики. Вони $\epsilon$ цікавими і корисними. Саме на деяких з них ми і зупинимо свою увагу в межах даної статті. 
Постановка завдання. Розкрити прикладну спрямованість математичного моделювання у задачах, які забезпечують базові фахові знання для виконання професійних завдань прикладного характеру за спеціальністю 271 - Річковий та морський транспорт.

Виклад основного матеріалу дослідження. Згідно з Модельними курсами IMO студенти повинні мати уявлення про центроїди основних геометричних фігур, а також уміти знаходити центроїди [8, с.151], [7, с.248], [6, с.217].

В математиці та фізиці центроїд або геометричний центр фігури - це середнє арифметичне положення усіх точок фігури. Неформально, це точка у якій фігура ідеально балансує на кінчику булавки. Іноді центроїд називають барицентром. У курсах інженерної математики поняття про центроїд вводиться наступним чином. Нехай ми маємо деяку пластинку, яка $є$ тонким пласким листком, що має однакову товщину. Центром тяжіння цієї пластинки є точка, де пластинка ідеально балансує, тобто центр мас пластинки. При роботі 3 певною фігурою (тобто пластинкою з незначною площиною та масою) термін центр фігури або центроїд використовується для точки, де буде знаходитись центр гравітації цієї фігури [2, с.378], [3, с.466]. Детальніше поняття про центроїд, а також його метричні характеристики розглянуто у статті Працьовитого М.В. [12].

Існує декілька методів знаходження положення центроїда. Одним 3 них $є$ інтегральний метод. Саме він знаходить своє відображення у курсі Higher Engineering Mathematics i, на наш погляд, ним варто доповнити традиційний вітчизняний курс вищої математики.

Координати центроїду $(\bar{x} ; \bar{y})$ в Декартовій прямокутній системі координат знаходять наступним чином:

- $\quad$ для випадку коли фігура обмежена кривою $y=f(x)$, прямими $x=a, x=b$ та віссю абсцис:

$$
\bar{x}=\frac{\int_{a}^{b} x y d x}{\int_{a}^{b} y d x}, \quad \bar{y}=\frac{\frac{1}{2} \int_{a}^{b} y^{2} d x}{\int_{a}^{b} y d x}
$$

- $\quad$ для випадку коли фігура обмежена кривою $x=f(y)$, прямими $y=c, y=d$ та віссю ординат:

$$
\bar{x}=\frac{\frac{1}{2} \int_{c}^{d} x^{2} d y}{\int_{c}^{d} x d y}, \quad \bar{y}=\frac{\int_{c}^{d} x y d y}{\int_{c}^{d} x d y} .
$$

Наведемо приклади декількох задач, які доцільно розглянути зі студентами, з метою якіснішого формування необхідних відповідних компетенцій, про які говорилось у вступній частині статті, а також у відповідних офіційних документах [6], [7], [8], [10].

Задача 1. Довести методом інтегрування, що центроїд прямокутника лежить у точці перетину його діагоналей [3, с.467].

Коментарі до розв'язування задачі 1. 3 метою демонстрації використання обох формул для знаходження центроїда, розв'яжемо задачу двома способами:

Перший спосіб. Нехай фігура обмежена $y=b$, прямими $x=0, x=l$ та віссю абсцис тоді за формулами (1):

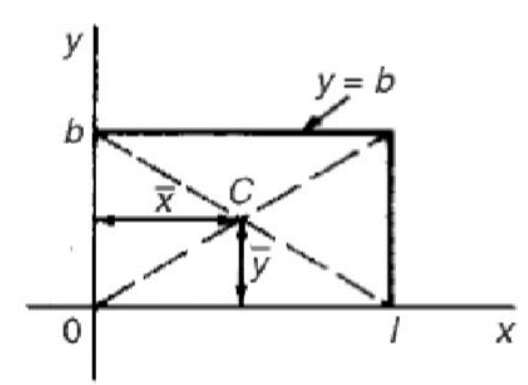

Рис. 1. Креслення до задачі 1 [3,с.467] 


$$
\begin{gathered}
\bar{x}=\frac{\int_{a}^{b} x y d x}{\int_{a}^{b} y d x}=\frac{\int_{0}^{l} x b d x}{\int_{0}^{l} b d x}=\frac{\left.b \frac{x^{2}}{2}\right|_{0} ^{l}}{\left.b x\right|_{0} ^{l}}=\frac{b \frac{l^{2}}{2}}{b l}=\frac{l}{2} \\
\bar{y}=\frac{\frac{1}{2} \int_{a}^{b} y^{2} d x}{\int_{a}^{b} y d x}=\frac{\frac{1}{2} \int_{0}^{l} b^{2} d x}{\int_{0}^{l} b d x}=\frac{\left.\frac{1}{2} b^{2} x\right|_{0} ^{l}}{\left.b x\right|_{0} ^{l}}=\frac{\frac{1}{2} b^{2} l}{b l}=\frac{b}{2} .
\end{gathered}
$$

Другий спосіб. Нехай фігура обмежена $x=l$, прямими $y=0, y=b$ та віссю ординат тоді за формулами (2):

$$
\begin{gathered}
\bar{x}=\frac{\frac{1}{2} \int_{c}^{d} x^{2} d y}{\int_{c}^{d} x d y}=\frac{\frac{1}{2} \int_{0}^{b} l^{2} d y}{\int_{0}^{b} l d y}=\frac{\left.\frac{1}{2} l^{2} y\right|_{0} ^{b}}{\left.l y\right|_{0} ^{b}}=\frac{\frac{1}{2} l^{2} b}{b l}=\frac{l}{2} \\
\bar{y}=\frac{\int_{c}^{d} x y d y}{\int_{c}^{d} x d y}=\frac{\int_{0}^{b} l y d y}{\int_{0}^{b} l d y}=\frac{\left.\frac{1}{2} y^{2} l\right|_{0} ^{b}}{\left.l y\right|_{0} ^{b}}=\frac{\frac{1}{2} b^{2} l}{b l}=\frac{b}{2} .
\end{gathered}
$$

Таким чином центроїд прямокутника має координати $(\bar{x} ; \bar{y})=\left(\frac{l}{2} ; \frac{b}{2}\right)$, тобто він дійсно знаходиться у точці перетину діагоналей прямокутника.

Аналогічно можна запропонувати студентам для розв'язування задачі, які доводять положення центроїда трикутника.

Задача 2. Знайдіть координати центроїда фігури, що обмежена кривою $y^{2}=9 x$ у межах $x=0, x=5$.

Коментарі до розв'язування задачі 2. Використання формул для знаходження центроїду, зазвичай, не викликає у студентів особливих труднощів у випадках коли відповідні функції виражені явно $y=f(x)$. Розв'язування таких прикладів наведено у підручниках [2], [3].

Як бути у нашому випадку? Зрозуміло, що ордината центроїду дорівнюватиме нулеві через симетричність параболи: $\bar{y}=0$.

Що ж до абсциси, то вона співпадатиме 3 абсцисою центроїда верхньої (або нижньої) половини фігури, що розглядається. Вони відповідно обмежуються графіками функцій:

$$
\begin{array}{ccc}
y=3 \sqrt{x}, & x=0, & x=5 \\
(y=-3 \sqrt{x}, & x=0, & x=5) .
\end{array}
$$

Знайдемо $\bar{x}$, керуючись вищенаведеними міркуваннями та формулами (1):

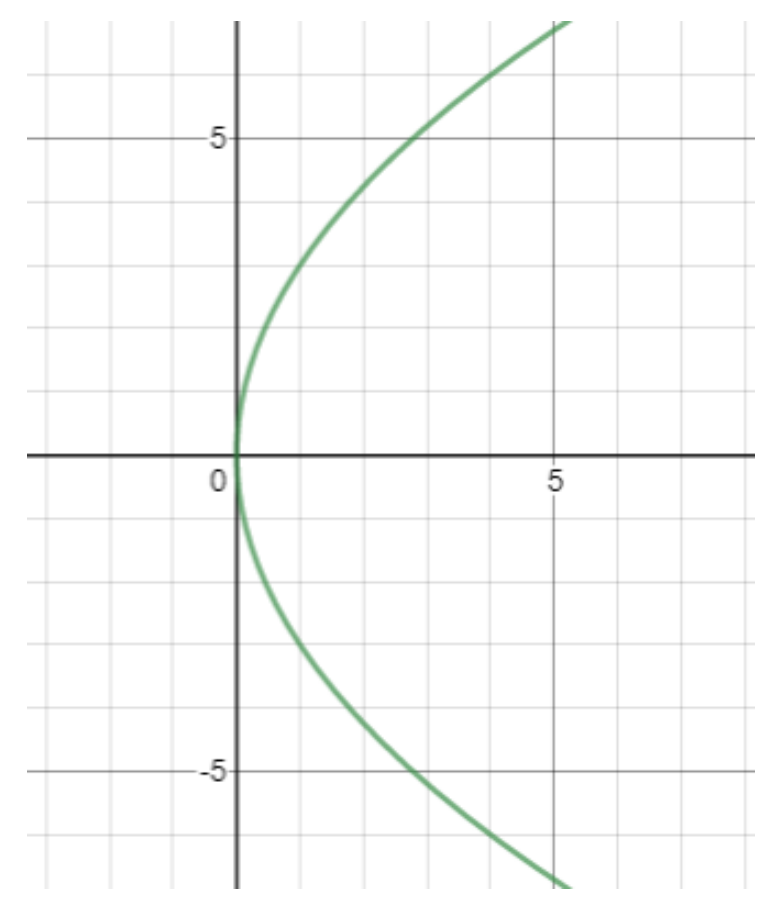

$$
\bar{x}=\frac{\int_{0}^{5} x y d x}{\int_{0}^{5} y d x}=\frac{\int_{0}^{5} 3 x \sqrt{x} d x}{\int_{0}^{5} 3 \sqrt{x} d x}=3 .
$$

Bidnoвidb. (3; 0).

Наведемо приклад задачі, яка демонструє використання уявлень про центроїд в інженерній математиці. 
Задача 3. Металевий диск має радіус 5,0 см і товщину 2,0 см. Напівкругле поглиблення діаметром 2,0 см обробляється центрально навколо ободу для формування шківа. Визначте, використовуючи теорему Паппа, об'єм та масу металу, який при цьому видаляється, а також об'єм і масу шківа, якщо густина металу складає 8000 кг $/ \mathrm{M}^{3}$ [2, с.382].

Коментарі до розв'язування задачі 3. Згадаємо відповідну теорему Паппа. Об'єм тіла, утвореного обертанням плоскої фігури навколо осі, що лежить у тій же площині і не перетинає фігуру, дорівнює площі фігури помноженої на довжину кола, радіусом якого є відстань від осі обертання до центроїду фігури. Таким чином він обчислюється за формулами:

$V=S \cdot \bar{y} \cdot 2 \pi \quad$ (якщо $\quad$ обертання відбувається навколо горизонтальної осі);

$V=S \cdot \bar{x} \cdot 2 \pi \quad$ (якщо $\quad$ обертання відбувається навколо вертикальної осі).

Розглянемо наступний переріз шківа (рис.3). Таким чином можна сказати, що:

1) обертаючи область $P Q R S$ навколо горизонтальної осі, отримуємо тіло обертання, об'єм якого дорівнює об'єму шківа, то який говориться в задачі;

2) обертаючи півкруг $P Q$ навколо горизонтальної осі, отримуємо тіло обертання, об'єм якого дорівнює об'єму металу, який при цьому видаляється.

Окремої уваги потребує обчислення об'єму тіла обертання, що описується півкругом

$P Q$. Нескладно показати що ордината центроїда (барицентру) знаходиться на відстані $d=\frac{4 r}{3 \pi}$ від центру відповідного круга [3, с.471]. Нехай

$$
V=S \cdot \bar{y} \cdot 2 \pi(\text { за теоремою Паппа), }
$$

де $V=\frac{4}{3} \pi r^{3}-$ об'єм кулі, що утворюється під час обертання півкруга;

$S=\frac{\pi r^{2}}{2}-$ площа півкруга;

$\bar{y}$ - ордината центроїда (барицентра) півкруга із центром у початку координат,

$2 \pi \bar{y}$ - відстань, яку проходить центроїд в результаті одного обертання навколо горизонтальної осі, тоді

$$
\begin{gathered}
\frac{4}{3} \pi r^{3}=\frac{\pi r^{2}}{2} \cdot \bar{y} \cdot 2 \pi \\
\bar{y}=\frac{4 r}{3 \pi}
\end{gathered}
$$

Таким чином ордината центроїду півкруга $P Q$ з радіусом $r=1$ см :

$$
\bar{y}=5-\frac{4 r}{3 \pi} \approx 4,576
$$


Використовуючи вказані данні можемо дати відповідь на перше питання задачі. А саме, знайти об’єм та масу, металу, що видаляється під час формування шківа:

$$
\begin{aligned}
& V=S \cdot \bar{y} \cdot 2 \pi \text { (за теоремою Паппа), } \\
& V_{\text {мет }}=\frac{\pi r^{2}}{2} \cdot\left(5-\frac{4 r}{3 \pi}\right) \cdot 2 \pi, \text { де } r=1 \\
& V_{\text {мет }} \approx 45,16 \mathrm{~cm}^{3}=45,16 \cdot 10^{-6} \mathrm{M}^{3}, \\
& m_{\text {мет }}=V_{\text {мет }} \rho=45,16 \cdot 10^{-6} \mathrm{M}^{3} \cdot 8000 \mathrm{\kappa} / \mathrm{M}^{3}=0,3613 \kappa \Gamma=361,3 г .
\end{aligned}
$$

Об’єм та масу шківа можна визначити як об'єм циліндра, що описує під час обертання навколо горизонтальної осі прямокутник $P Q R S$, за мінусом об'єму металу, що видаляється під час формування шківа:

$$
V_{\text {шківа }}=\pi R^{2} H-45,16
$$

$$
V_{\text {шківа }} \approx \pi \cdot 5^{2} \cdot 2-45,16=111,9 \mathrm{~cm}^{3}=111,9 \cdot 10^{-6} \mathrm{M}^{3},
$$

$m_{\text {шківа }} \approx 895,2$ г.

Задача розв'язана.

Запропонований підхід для знаходження об'єму шківа $\epsilon$ доцільним 3 огляду на рекомендації IMO [8, с.151], [7, с.248], [6, с.218].

Також можна запропонувати студентам знайти об'єм шківа за традиційною формулою

$$
V=\pi \int_{a}^{b} f^{2}(x) d x
$$

Зрозуміло, що шків є тілом обертання нижньої частини кола з радіусом 1. Припустимо (для зручності), що центр кола знаходиться на осі $O Y$. Тоді рівняння відповідного кола матиме рівняння $x^{2}+(y-5)^{2}=1$. Для того щоб використати вищенаведену формулу знаходження об'єму необхідно подати рівняння кола у вигляді явної функції $y=$ $\pm \sqrt{1-x^{2}}+5$. Зрозуміло, що функція функції $y=\sqrt{1-x^{2}}+5$ описуватиме верхню частину півкола, а функції $y=-\sqrt{1-x^{2}}+5$ описуватиме нижню частину півкола. Таким чином отримуємо:

$$
\begin{gathered}
V_{\text {шківа }}=\pi \int_{-1}^{1}\left(5-\sqrt{1-x^{2}}\right)^{2} d x ; \\
V_{\text {шківа }}=\pi \int_{-1}^{1}\left(25-10 \sqrt{1-x^{2}}+\left(1-x^{2}\right)\right) d x .
\end{gathered}
$$

Окремої уваги потребує обчислення інтегралу $\int_{-1}^{1} \sqrt{1-x^{2}} d x$. Одним із шляхів його обчислення є інтегрування методом тригонометричної підстановки

$$
\begin{gathered}
\int_{-1}^{1} \sqrt{1-x^{2}} d x=\left|\begin{array}{cc}
x=\sin t & 1=\sin _{2} \rightarrow t_{2}=\frac{\pi}{2} \\
d x=\cos t d t & -1=\sin t_{1} \rightarrow t_{1}=-\frac{\pi}{2}
\end{array}\right|= \\
-\pi 2 \pi 21-\sin 2 t \cos t d t=-\pi 2 \pi 2 \cos 2 t d t=-\pi 2 \pi 2121+\cos 2 t d t=12 t+12 \sin 2 x \pi 2-\pi 2=\pi 2 .
\end{gathered}
$$

Такий варіант розв'язування є доцільним, якщо ставиться за мету продемонструвати використання вищенаведеної тригонометричної підстановки, нагадати студентам відповідні особливості інтегрування тригонометричних функцій, а також деякі тригонометричні формули, актуалізація яких відповідає рекомендаціями IMO [8, с.150], [7, с.248]. 
Можливий також і інший шлях обчислення інтегралу $\int_{-1}^{1} \sqrt{1-x^{2}} d x$, який представлено у шкільних підручниках [4] та зовнішньому незалежному оцінюванню (№30, 2012 рік (перша сесія)) [5]:

$$
\int_{-1}^{1} \sqrt{1-x^{2}} d x=\frac{1}{2} S_{\text {круга }}=\frac{1}{2} \pi R^{2}=\frac{1}{2} \pi 1^{2}=\frac{\pi}{2}
$$

де $S_{\text {круга }}$ - площа круга, що обмежене колом $x^{2}+y^{2}=1$ (відповідно рівняння верхнього півкола має вигляд $y=\sqrt{1-x^{2}}$ ).

Такий варіант розв'язування є доцільним, якщо ставиться за мету продемонструвати використання геометричного змісту визначеного інтегралу або вищенаведені тригонометричні підстановки не були опановані студентами через брак часу.

Повернемось до обчислення об’єму шківа:

$$
\begin{gathered}
V_{\text {шківа }}=\pi \int_{-1}^{1}\left(25-10 \sqrt{1-x^{2}}+\left(1-x^{2}\right)\right) d x ; \\
V_{\text {шківа }}=\left.\pi\left(25 x+x-\frac{x^{3}}{3}\right)\right|_{-1} ^{1}-10 \int_{-1}^{1}\left(\sqrt{1-x^{2}}\right) d x ; \\
V_{\text {шківа }}=\pi\left(50+2-\frac{2}{3}\right)-5 \pi ; \\
V_{\text {шківа }} \approx 111,9 \mathrm{~cm}^{3} .
\end{gathered}
$$

Вidnoвidb. Об'єм видаленого металу: $\approx 45,16 \mathrm{~cm}^{3}=45,16 \cdot 10^{-6} \mathrm{M}^{3}$; маса видаленого металу: $\approx 0,3613$ кг = 361,3 г; об’єм шківа: $\approx 111,9 \mathrm{~cm}^{3}$; маса шківа: $\approx 895,2$ г.

Висновки. Інтегральний метод знаходження положення центроїду суттєво збагатить курс вищої математики, а також, безперечно, стане ще однією вдалою позицією інтегровності природничо-математичних компетентностей до професійної підготовки майбутніх фахівців річкового та морського транспорту. Подальшого дослідження набувають напрями формування блоку різнопланових задач із використання фундаментальних основ вищої та інженерної математики для студентів молодших курсів морських спеціальностей

\section{ЛITEPАТУРА}

1. Википедия. Свободная энциклопедия. URL: https://ru.wikipedia.org/wiki/Teopeмы_ Паппа___ Гульдина

2. Jonn Bird. Higher Engineering Mathematics. 2006. 726 p.

3. Jonn Bird. Engineering Mathematics. 2003. - 531 p.

4. Алгебра: підруч. для 11 кл. 3 поглибленим вивченням математики: у 2 ч./ А.Г.Мерзляк, Д.А.Номіровський, В.Б.Полонський, М.С.Якір. Харків: Гімназія, 2011. 272 с.

5. ЗНО онлайн з математики. URL: https://zno.osvita.ua/mathematics/3/

6. Model Course 7.03 Officer in charge of a Navigational watch by IMO (International Maritime Organization. 2014 Edition.

7. Model Course 7.04 Officer in charge of an Engineering watch by IMO (International Maritime Organization. 2014 Edition.

8. Model Course 7.08 Electro - technical officer by IMO (International Maritime Organization. 2014 Edition.

9. Math 24. Pappus's Theorem. URL: https://www.math24.net/pappus-theorem/

10. Стандарт вищої освіти України. Перший (бакалаврський) рівень вищої освіти. Галузь знань - 27 Транспорт, спеціальність - 271 Річковий та морський транспорт. [Чинний від 13.11.2018 № 1239.] Вид. офіц. Київ : Міністерство освіти і наукиУкраїни, 2018. 
11. Про внесення змін у додаток до постанови Кабінету Міністрів України від 23 листопада 2011 р. № 1341: постанова Кабінету Міністрів України від 12 червня 2019 р. № 509). URL: https://zakon.rada.gov.ua/laws/show/509-2019-п

12. Працьовитий М., Одинець Ю. Геометрія мас і барицентричний метод розв'язування планіметричних задач. Педагогічні науки: теорія, історія, інновачійні технології. 2016. № 3 (57). С. $327-340$

\section{REFERENCES}

1. Vikipediia. Vilna entsyklopediia URL: https://ru.wikipedia.org/wiki/Tеоремы_ Паппа_— Гульдина

2. Jonn Bird. Higher Engineering Mathematics. 2006. 726 p.

3. Jonn Bird. Engineering Mathematics. 2003. - 531 p.

4. Alhebra: pidruch. dlia $11 \mathrm{kl}$. $\mathrm{z}$ pohlyblenym vyvchenniam matematyky: $\mathrm{u} 2 \mathrm{ch} . /$ A.H.Merzliak, D.A.Nomirovskyi, V.B.Polonskyi, M.S.Iakir. Kharkыv: Himnaziia, 2011.272 s

5. ZNO onlain z matematyky. URL: https://zno.osvita.ua/mathematics/3/

6. Model Course 7.03 Officer in charge of a Navigational watch by IMO (International Maritime Organization. 2014 Edition.

7. Model Course 7.04 Officer in charge of an Engineering watch by IMO (International Maritime Organization. 2014 Edition.

8. Model Course 7.08 Electro - technical officer by IMO (International Maritime Organization. 2014 Edition.

9. Math 24. Pappus's Theorem. URL: https://www.math24.net/pappus-theorem/

10. Standart vyshchoi osvity Ukrainy. Pershyi (bakalavrskyi) riven vyshchoi osvity. Haluz znan 27 Transport, spetsialnist - 271 Richkovyi ta morskyi transport. [Chynnyi vid 13.11.2018 № 1239.] Vyd. ofits. Kyiv : Ministerstvo osvity i naukyUkrainy, 2018.

11. Pro vnesennia zmin u dodatok do postanovy Kabinetu Ministriv Ukrainy vid 23 lystopada 2011 r. № 1341: postanova Kabinetu Ministriv Ukrainy vid 12 chervnia 2019 r. № 509). URL: https://zakon.rada.gov.ua/laws/show/509-2019-p

12. Pratsovytyi M., Odynets Yu. Heometriia mas i barytsentrychnyi metod rozviazuvannia planimetrychnykh zadach. Pedahohichni nauky: teoriia, istoriia, innovatsiini tekhnolohii. 2016. № 3 (57). S. 327-340

Клиндухова В.Н., Гейлик А.В., Ляшко О.В. МОДЕЛИРОВАНИЯ НЕКОТОРЫХ ОБЬЕКТОВ СРЕДСТВАМИ ИНТЕГРАЛЬНОГО ИСЧИСЛЕНИЯ СТУДЕНТАМИ МЛАДШИХ КУРСОВ МОРСКИХ СПЕЦИАЛЬНОСТЕЙ

Статья посвящена актуальному вопросу прикладной направленности дисциплин математического ицкла, моделированию инженерных процессов средствами традиционного курса высшей математики и использования теории центра масс.

Вопрос интегрированности компетенций профессиональной подготовки специилистов речного и морского транспорта в систему математических дисииплин всегда вызывало интерес. Учитывая, что данная специальность является регулируемой и имплементирована в мировое общество, к математическим знаниям студентов младиих курсов морских специальностей выдвигается ряд требований. Замечено, что некоторые вопросы инженерной математики, которые отражаются в международных требованиях Модальных курсов IМО, в то же время не совсем полностью отражены в курсе математических дисциплин морских $3 В О$.

Предложенные задачи в полной мере отражают связь математической подготовки с образовательно-профессиональными программами подготовки специалистов речного $u$ морского транспорта, Стандартами высшего образования Украины и международными 
требованиями ІМО. Каждая зададача включает комментарий $\kappa$ решению, а также рассматривается с позиций как традиционности преподавания высшей математики, так $и$ с помощью теории о иентре масс.

В свою очередь, интегральный метод решения задач на нахождение центроида позволяет не только усовершенствовать базовые знания по высшей математике, но $u$ заинтересовать и мотивировать студента $\kappa$ повышению уровня математических профессиональных навыков, формированию профессиональных задач в основне которых будут лежать фундаментальные математические утверждения, методы, средства.

Дальнейтего исследования требуют вопросы разработки и совершенствования методической системы заданий дисииллин математического иикла в соответствии с требованиями образовательно-профессиональных программ подготовки специалистов речного и морского транспорта, Стандартов высшего образования и Модальные курсов ИМО. В аспекте этого направления развития исследований особого внимания требуют конщептуальные вопросы Higher Engineering Mathematics, интегрируемость математических и профессиональных компетенций.

Ключевые слова: моделирование объектов, подготовка специалистов речного и морского транспорта, професионально-математическая подготовка, цееттроид, барицентра, центр мacc.

Klindukhova V., Heilyk A., Liashko O.

MODELING OF SOME OBJECTS BY MEANS OF INTEGRAL CALCULUS BY JUNIOR STUDENTS OF MARINE SPECIALTIES

The article is devoted to the urgent issue of the applied orientation of the disciplines of the mathematical cycle, modeling of engineering processes by means of the traditional course of higher mathematics and the use of the theory of the center of mass.

The issue of the integration of competencies of professional training of river and sea transport specialists in the system of mathematical disciplines has always been of interest. Given that this specialty is regulated and implemented in world society, a number of requirements are put forward to the mathematical knowledge of junior students of marine specialties. It is noted that some issues of engineering mathematics, which are reflected in the international requirements of IMO Modal courses, are at the same time not completely reflected in the course of mathematical disciplines of marine institution of higher education.

The proposed tasks fully reflect the connection of mathematical training with educational and professional training programs for river and sea transport specialists, the Higher Education Standards of Ukraine and the international IMO requirements. Each task includes a commentary on the solution, and is also considered from the standpoint of both the tradition of teaching higher mathematics and with the help of the theory of the center of mass.

In turn, the integral method for solving problems of finding a centroid allows not only improving basic knowledge of higher mathematics, but also interest and motivate students to increase the level of mathematical professional skills, the formation of professional problems which will mainly be based on fundamental mathematical statements, methods, tools .

Further research requires the development and improvement of the methodological system of assignments for the disciplines of the mathematical cycle, in accordance with the requirements of educational and professional training programs for river and sea transport specialists, Higher Education Standards and IMO Modal Courses. In the aspect of this direction of research development, particular attention is required to the conceptual questions of Higher Engineering Mathematics, the integrability of mathematical and professional competencies.

Keywords: object modeling, training of river and sea transport specialists, professional and mathematical training, centroid, barycenter, center of mass. 